\title{
Our Systematic Reviews Are Important and Relevant - Reply to Vickers
}

\author{
Myeong Soo Lee $\mathrm{L}^{\mathrm{a}, \mathrm{b}} \quad$ Edzard Ernst ${ }^{\mathrm{b}}$ \\ ${ }^{a}$ Brain Disease Research Center, Korea Institute of Oriental Medicine, Daejeon, South Korea \\ ${ }^{\mathrm{b}}$ Complementary Medicine, Peninsula Medical School, University of Exeter, Exeter, UK
}

In his editorial, Andrew Vickers [1] made an interesting albeit obvious observation: the methods sections and conclusions of our acupuncture reviews are similar. Therefore, he argued that they are 'meaningless re-analyses of published trials'. We beg to differ: 'Systematic reviews' should identify and review all the relevant studies and are more likely to give a reliable answer. They use explicitly defined methods and quality standards to reduce bias. Their results are the closest we are likely to get to the truth in the current state of knowledge, though much depends on how many clinical trials exist and how good and how large they are. Systematic reviews (and meta-analyses, the statistical combining of information from many trials) are our best defence against making incorrect decisions based on inadequate data [2]. In addition, our mentioned acupuncture reviews give people the opportunity to access studies originally published in languages which they would otherwise be unable to read.

Being 'our best defence' [2], systematic reviews cannot be truly meaningless. Using 'explicitly defined methods', they have to adhere to rigid protocols which would produce rather similar method sections. In the case of acupuncture, evidence is frequently flawed and inconclusive. How many ways exist to express this situation? Our point is that systematic reviews are almost similar by definition. We ask ourselves why Vickers selected our reviews from the much larger pool of similar articles by other researchers?
Vickers wonders why he has never heard of acupuncture/ moxibustion being used for schizophrenia, chemotherapyinduced nausea or hot flashes in men with prostate cancer. Could this be because he is neither a clinician nor a well-read acupuncture expert? Or is it because he only reads in the English language and many of the studies are not published in that language? In our view, the fact that all of these reviews included sizable numbers of clinical trials already demonstrates clinical relevance. As our reviews acquainted Vickers with the above named topics, this means that they have served a purpose.

We are convinced that the decision whether or not any given systematic review contributes meaning to advancing science or reducing human suffering is best made by experts, i.e. the reviewers and editors of top journals. And in the cases cited by Vickers, these decisions were clearly positive.

\section{References}

1 Vickers AJ: Reducing systematic review to a cut and paste. Forsch Komplementmed 2010;17:303-305.

2 Moore A, McQuay H: Bandolier's Little Book of Making Sense of the Medical Evidence. Oxford, Oxford University Press, 2006.

\section{KARGER \\ Fax +497614520714 \\ Information@Karger.de}

www.karger.com (c) 2011 S. Karger GmbH, Freiburg

1661-4119/11/0183-0155\$38.00/0

Accessible online at:

www.karger.com/fok
Edzard Ernst, MD, PhD, FMedSci, FSB, FRCP, FRCPEd

Complementary Medicine, Peninsula Medical School

University of Exeter

Salmon Pool Lane, Exeter, EX2 4SG, UK

edzard.ernst@pms.ac.uk 